\title{
Predictive Factors for Postoperative Severe Hypocalcaemia after Parathyroidectomy for Primary Hyperparathyroidism
}

NICOLA CREA, M.D.,* GIACOMO PATA, M.D.,† CLAUDIO CASELLA, M.D.,* CARLO CAPPELLI, M.D., BRUNO SALERNI, M.D.*

From the *Department of Medical and Surgical Sciences, First Division of General Surgery, University of Brescia, Brescia, Italy; the TSecond Department of General Surgery, Brescia Civic Hospital, Brescia, Italy; and the $\neq$ Department of Medical and Surgical Sciences, Clinica Medica, University of Brescia, Brescia, Italy

Hypocalcaemia is a complication of parathyroidectomy. We retrospectively analyzed data on patients who underwent parathyroidectomy for primary hyperparathyroidism (pHPT) to identify predictive factors for severe postoperative hypocalcaemia. Since 2004 we performed 87 parathyroidectomies for pHPT. We divided the patients into two groups: subjects who presented with postoperative hypocalcaemia (group B) or otherwise (group A). We looked for a correlation between several variables and the incidence of postoperative hypocalcaemia. The median calcemia in group B (19 patients) was $6.9 \mathrm{mg} / \mathrm{dL}$ on the first postoperative day and $7.6 \mathrm{mg} / \mathrm{dL}$ on the third day. We observed hypocalcemia related clinical symptoms in every patient. In all 19 cases the reduction of intraoperative parathyroid hormone above 85 per cent after parathyroidectomy was related to the development of severe postoperative hypocalcaemia $(P=0.042)$. We found that the reduction of intraoperative parathyroid hormone over 85 per cent after parathyroidectomy can be considered a reliable predictive factor of postoperative hypocalcaemia after parathyroidectomy for primary hyperparathyroidism.

$\mathrm{P}$ RIMARY HYPERPARATHYROIDISM (pHPT) is an increasingly common endocrine disorder with a higher incidence between the fifth and seventh decade of life. ${ }^{1-9}$ In more than 70 per cent of cases it is due to single adenomas whereas in 10 to 20 per cent of cases it is caused by multiglandular disease, like double adenomas or hyperplasia, $1,2,5,10-14$ and it is rarely secondary to parathyroid cancer. $1,2,10,11,15,16$

Over the years many different therapeutic approaches have been proposed to treat pHPT and, among all these, parathyroidectomy represents a mainstay in case of symptomatic pHPT, with a percentage of success over 95 per cent. It is also indicated in selected asymptomatic patients. ${ }^{17-23}$ It has been demonstrated that patients who underwent parathyroidectomy have a lower risk of mortality, onset of cardiovascular complications, and even pHPT-related tumors than patients who were not operated. ${ }^{1,2,6,24-30}$ However, parathyroidectomy can be followed by life-threatening perioperative complications such as severe hypocalcaemia. ${ }^{31-44}$ The incidence of

Address correspondence and reprint requests to Nicola Crea, M.D., Department of Medical and Surgical Sciences, First Division of General Surgery, University of Brescia, Viale Europa 11, 25123 Brescia, Italy. E-mail: cirioz@libero.it. transient postoperative hypocalcaemia rates from 0 per cent to 35 per cent, ${ }^{36-46}$ whereas a permanent hypocalcaemia occurs in 0 per cent to 3.8 per cent of cases. ${ }^{45-48}$

At present, no specific causes have been disclosed to explain the onset of postoperative hypocalcaemia that still remains a postparathyroidectomy multifactorial syndrome. ${ }^{36-39,} 49$ Moreover, this syndrome has an important role in the postoperative management of patients who underwent parathyroidectomy because in case of severe hypocalcaemia a longer clinical observation and hospital stay associated to a supplementation of calcium and Vitamin D are required. In this light, the identification of predictive factors for the development of postoperative hypocalcaemia would be beneficial; this would allow surgeons to select patient candidates for parathyroidectomy on an outpatient or a short-stay basis. $36,37,39,40,44,45,47,48$

This study aimed to identify possible predictive factors for the onset of postoperative hypocalcaemia after parathyroidectomy for $\mathrm{pHPT}$.

\section{Patients and Methods}

We retrospectively analyzed the data of 87 patients undergoing surgery for pHPT between June 2004 and December 2009. For all these patients we considered 
gender, age, symptoms experienced, symptom-diagnosis latency, and any previous neck surgery. We recorded the data of perioperative laboratory tests, specifically serum concentration of calcium, parathyroid hormone (PTH), alkaline phosphatase (AP), creatinine, magnesium, potassium, bicarbonates, phosphates, albumin, and serum $\mathrm{pH}$ value. We evaluated the reduction in intraoperative PTH (i.o. PTH) expressed as a percentage defined using the following formula: [(PTH at induction - i.o. PTH after 10 minutes from the parathyroidectomy)/ PTH at induction] $\times 100$.

Quick i.o. PTH was determined using a solid-phase chemiluminescent immunometric assay (Immulite Analyser Turbo Intact PTH, Medical System, Genoa, Italy). All the blood samples were taken from peripheral veins. We also recorded the results of the histological examination, with particular reference to the weight of the parathyroid adenoma, postoperative calcaemia, the presence of any hypocalcaemia-induced clinical symptoms (paraesthesia, cramps, Chvostek sign, Trousseau sign), and the duration of the hospital stay.

We defined postoperative hypocalcaemia as a serum calcium level $<8 \mathrm{mg} / \mathrm{dL}$ in one measurement recorded within 4 days of the parathyroidectomy. ${ }^{50}$ Severe hypocalcemia was defined as serum calcium levels below $7.5 \mathrm{mg} / \mathrm{dL}$.

We looked for statistical correlation between the variables considered and the incidence of postoperative severe hypocalcaemia by splitting the subjects into two groups: patients who did not present postoperative severe hypocalcaemia (group A) and patients who experienced such complication (group B).

We scheduled follow-up with clinical and biochemical examinations 1 week and 1, 6, and 12 months after surgery. At each follow-up meeting we recorded serum calcium, Vitamin D, and PTH values, and vitamin D metabolic complications. The mean follow-up was 12.6 months (range 18.7-10.0 months) to identify the onset of any recurrent or persistent pHPT.

\section{Statistical Analysis}

Chi-squared or Fisher's exact tests were used when appropriate to compare categorical variables; logistic regression models were used in univariate and multivariate analyses to identify the factors related to post operative severe hypocalcemia. For each analysis the following potential predictive variables were taken into account: age, gender, previous neck surgery (yes/ no), preoperative serum calcium, PTH, AP, creatinine, magnesium, potassium, bicarbonates, phosphates, albumin concentration, the weight of the parathyroid adenoma, and the reduction of i.o. PTH.

Finally, Receiver Operating Characteristic (ROC) curves were constructed when appropriate. The level of statistical significance was set at $P<0.05$. All tests were two-sided. Statistical analysis was performed with statistical software for biomedical research (MedCalc ${ }^{\circledR}$ Software for Windows, Version 9.2.0.0, MedCalc Software, Mariakerke, Belgium).

\section{Results}

The median age of the patients studied (61 female and 26 male) was 63.9 years. Among all the 87 subjects, 68 (78.2\%) did not present severe hypocalcemia after parathyroidectomy (group A), whereas 19 patients suffered from severe postoperative (PO) hypocalcemia with serum calcium level lower than $7.5 \mathrm{mg} / \mathrm{dL}$. Table 1 indicates the characteristics of the two groups of patients considered.

\section{Group A}

The median age among group A (49 females and 19 males) was 62.3 years (range 29-78 years). Overall, the preoperative clinical manifestation of pHPT were: renal in 33 cases $(48.5 \%)$; 18 patients $(26.5 \%)$ had bone alterations, 8 patients $(11.8 \%)$ suffered neurological and/or mental disorders, and 17.4 per cent of patients (12 cases) were asymptomatic. Symptom-diagnosis latency varied from 3 to 54 months. Eleven patients (16.2\%) were on chronic therapy with diuretics and two patients $(2.9 \%)$ were on calcium antagonists.

Preoperative hypercalcemia was present in all patients $(100 \%$ ), with median values of $13.1 \mathrm{mg} / \mathrm{dL}$ (range $10.1-19.8 \mathrm{mg} / \mathrm{dL}$ ) and in 10 cases $(14.7 \%)$ alkaline phosphatase was elevated. No patient had low albumin values or serum $\mathrm{pH}$ alterations. All patients (100\%) had preoperative PTH values above the normal range: median value 410 (range $97-1450 \mathrm{pg} / \mathrm{mL}$ ). A single parathyroidectomy was performed in 61 cases $(89.7 \%)$.

The histological examination showed the presence of a parathyroid adenoma in all cases $(100 \%)$. The median weight of the adenoma was 550 milligrams (range

TABLE 1. Characteristics of Patients Undergoing Parathyroidectomy for Primary Hyperparathyroidism According to the Presentation of Postoperative Hypocalcaemia (Group B) or Otherwise (Group A)

\begin{tabular}{lcc}
\multicolumn{1}{c}{ Variable } & Group A & Group B \\
\hline Mean age & 62.3 years & 66.4 years \\
F/M gender ratio & 2.6 & 1.7 \\
Preoperative Ca+ & $13.1 \mathrm{mg} / \mathrm{dL}$ & $12.3 \mathrm{mg} / \mathrm{dL}$ \\
Ca+ 1st postoperative day & $8.5 \mathrm{mg} / \mathrm{dL}$ & $6.9 \mathrm{mg} / \mathrm{dL}$ \\
Ca+ 3rd postoperative day & $8.7 \mathrm{mg} / \mathrm{dL}$ & $7.6 \mathrm{mg} / \mathrm{dL}$ \\
Preoperative PTH & $410 \mathrm{pg} / \mathrm{mL}$ & $390 \mathrm{pg} / \mathrm{mL}$ \\
Change i.o. PTH \% & $77.0 \%$ & $89.7 \%$ \\
10 minutes & & \\
Weight of the adenoma & 550 grams & 635 grams \\
\hline
\end{tabular}

Data are given as a median \pm standard deviation unless otherwise indicated. 
360-1800 milligrams). The i.o. PTH level measured at the induction of anesthesia and 10 minutes from the parathyroidectomy revealed a median drop of 77 per cent (range 65-88\%).

In the first and third postoperative days, none of the patients had median calcaemia values lower than normal range $(8.5 \mathrm{mg} / \mathrm{dL}$, range $8.3-9.0 \mathrm{mg} / \mathrm{dL}$ and $8.7 \mathrm{mg} / \mathrm{dL}$, range $8.6-9.3 \mathrm{mg} / \mathrm{dL}$, respectively) and none presented any clinical symptoms of hypocalcaemia. The pre and postoperative values of serum creatinine, phosphate, magnesium, potassium, bicarbonate, and $\mathrm{pH}$ were also found to be normal. No calcium and vitamin D supplies were administered. Median time for discharge was 3.5 days (range 3.0-4.5) and none of the patients presented persistent or recurrent pHPT at follow-up controls.

\section{Group B}

The median age in group B (12 females and 7 males) was 66.4 years (range 35-74 years). Nine patients out of the 19 presented preoperatively with renal symptoms; bone alterations were observed in five cases $(26.3 \%)$ and 2 patients $(16.7 \%$ ) had neurological and/or mental disorders, whereas 3 patients were asymptomatic. Symptom-diagnosis latency varied from 3 to 48 months.

Two patients $(10.5 \%)$ were on chronic therapy with diuretics, 1 patient $(5.3 \%)$ was on angiotensin converting enzyme (ACE) inhibitors, and 1 patient (5.3\%), digitalis therapy. Blood examinations revealed a median serum calcium value of $12.3 \mathrm{mg} / \mathrm{dL}$ (range $10.8-20 \mathrm{mg} / \mathrm{dL}$ ), preoperative alkaline phosphatase was elevated in 3 patients $(15.8 \%)$, and serum $\mathrm{pH}$ and albumin values were within the normal range. All patients had a preoperative PTH value above the normal range: median value $390 \mathrm{pg} / \mathrm{mL}$ (range $91-1600 \mathrm{pg} / \mathrm{mL}$ ). None of the patients had had previous neck surgery. Sixteen patients $(84.2 \%)$ underwent simple parathyroidectomy.

The histological response in all cases demonstrated the presence of an adenoma, with a median weight of 635 milligrams(range 400-1650 milligrams). The mean reduction in i.o. PTH was 89.7 per cent (range 86-97.5\%).

The median serum calcium value on the first postoperative day was $6.9 \mathrm{mg} / \mathrm{dL}$ (range $6.3-7.4 \mathrm{mg} / \mathrm{dL}$ ) and on the third postoperative day it was $7.6 \mathrm{mg} / \mathrm{dL}$ (range $6.8-7.8 \mathrm{mg} / \mathrm{dL}$ ). The pre and postoperative values of serum creatinine, phosphate, magnesium, potassium, bicarbonate, and $\mathrm{pH}$ were within normal range.

All patients presented hypocalcaemia-related clinical symptoms, paraesthesia, cramps, Chvostek sign, and Trousseau sign, and were administered with parenteral and/or oral calcium and vitamin D until their calcaemia values normalized and the hypocalcaemia-related symptoms had disappeared. Patients were discharged when their serum calcium level was higher than $8 \mathrm{mg} /$ dL. Median time to discharge was 5.5 days (range 6.0-
8.5 days). All patients had normal calcemia values 6 months from the procedure. None of the patients presented with persistent hypoparathyroidism or persistent or recurrent pHTP at each follow-up meeting.

\section{Risk Factors For Postoperative Severe Hypocalcemia}

At univariate analysis, only i.o. PTH reduction was found to be predictive of postoperative severe hypocalcemia. Conversely, preoperative serum PTH and calcium levels, as well as patients' gender, age, parathyroid adenoma weight, previous neck surgery, surgical approach, AP, creatinine, magnesium, potassium, bicarbonate, and albumin serum concentration were not significantly correlated to postoperative severe hypocalcemia.

Significantly, at multivariate analysis, the i.o. PTH reduction was confirmed as independent risk factor for postoperative severe hypocalcemia (Table 2).

The ROC-curve analysis for intraoperative reduction showed a significant area under the curve (Fig. 1). In particular, i.o. PTH reduction as high as 85 per cent was found to be the most reliable cut-off for postoperative severe hypocalcemia (odds ratio 93, 95\%confidence interval 11 to $773, P=0.0001)$.

\section{Discussion}

Postoperative hypocalcaemia is one of the most important and potentially most dangerous complications of

TABLE 2. Univariate and Multivariate Analyses of Risk Factors of Severe Postoperative Hypocalcemia

\begin{tabular}{lcc}
\multicolumn{1}{c}{$\begin{array}{c}\text { Independent } \\
\text { Variables }\end{array}$} & $\begin{array}{c}\text { Univariate } \\
\text { Analysis } \\
P \text {-value }\end{array}$ & $\begin{array}{c}\text { Multivariate } \\
\text { Analysis } \\
P \text {-value }\end{array}$ \\
\hline $\begin{array}{l}\text { Preoperative serum } \\
\text { PTH level }\end{array}$ & 0.8 & - \\
$\begin{array}{l}\text { Preoperative serum } \\
\text { calcium level }\end{array}$ & 0.57 & - \\
i.o. PTH level & $<0.0001$ & 0.042 \\
Preoperative K+ serum level & 0.76 & - \\
Preoperative Na+ serum level & 0.65 & - \\
Preoperative PA serum level & 0.55 & - \\
Preoperative creatinine & 0.82 & - \\
$\quad$ serum level & 0.75 & - \\
Preoperative & & - \\
$\quad$ Mg++ serum level & 0.45 & - \\
Preoperative albuminemia & 0.6 & - \\
Operative time & & - \\
Surgical approach (unilateral/ & 0.44 & - \\
$\quad$ bilateral neck exploration) & & - \\
Parathyroid adenoma weight & 0.31 & - \\
Gender & 0.57 & - \\
Age & 0.45 & - \\
Previous neck surgery & 0.77 &
\end{tabular}

Of all the variables tested in univariate analysis, only those with $P$ values $\leq 0.05$ were entered into multivariate analyses in a stepwise manner until all variables remaining in the model were significant.

PA, alkaline phosphate. 


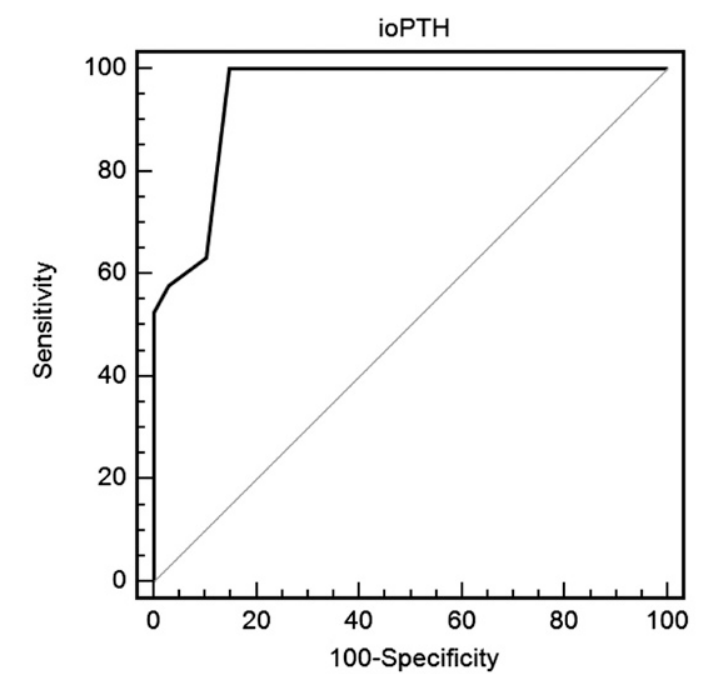

\begin{tabular}{|l|l|}
\hline Area under the ROC curve (AUC) & 0.950 \\
\hline Standard Error & 0.0357 \\
\hline 95\% Confidence Interval & 0.880 to 0.985 \\
\hline z statistic & 12.590 \\
\hline Significance level P (Area $=0.5)$ & 0.0001 \\
\hline For i.o.PTH drop $>85 \%$ & $\begin{array}{l}\text { Sensitivity }=100 \% \\
\text { Specificity }=85.3 \%\end{array}$ \\
\hline
\end{tabular}

FIG. 1. ROC-curve analysis. Variable: i.o. PTH drop. Outcome: severe postoperative hypocalcemia.

parathyroidectomy, with a multifactorial pathogenesis. ${ }^{36-55}$ We considered severe hypocalcaemia as postoperative serum calcium level $<7.5 \mathrm{mg} / \mathrm{dL}$. A possible cause of temporary or permanent symptomatic hypoparathyroidism is parathyroid gland damage, which can be caused by inadvertent removal of parathyroid tissue, but is more commonly caused by devascularization because the blood supply to the parathyroid glands from the inferior thyroid artery is limited and sensitive to surgical manipulation; other factors include direct trauma to the parathyroid gland causing haematoma. ${ }^{37}, 38,45,51$

Many authors have reported a significant reduction in the incidence of postparathyroidectomy hypocalcaemia by performing a unilateral exploration in cases of pHPT. ${ }^{38,52,53,55}$ Moreover the onset of hypocalcaemia could be dependent from calcitonin hyperincretion, due to thyroid manipulation, and perioperative calcium hemodilution. ${ }^{37,49}$ The main mechanism is probably the inadequate parathyroid function caused by a slow or delayed functional recovery of the residual parathyroid tissue after hyper-functioning adenoma removal. ${ }^{46,54}$ Post-parathyroidectomy hypocalcaemia can also be caused by a rapid recovery of calcium uptake by the skeleton (hungry bone syndrome). ${ }^{45}$
Temporary hypocalcaemia has been reported to occur in 0 per cent to 35 per cent of patients after parathyroidectomy, whereas permanent hypoparathyroidism occurs after parathyroidectomy in 0 per cent to 3.8 per cent of cases. ${ }^{1,36,38,43,45,46}$ In our experience the incidence of temporary postparathyroidectomy hypocalcaemia was 21.8 per cent (19/87 patients). Higher incidences of temporary and permanent hypocalcaemia (> 40\%) are recorded in patients undergoing repeated surgery for persistent or recurrent pHPT. ${ }^{47,48}$ A significant drop in calcium is often not evident until the third or fourth postoperative days. ${ }^{37}$

Symptomatic hypocalcaemia plays an important role in delaying hospital discharge, and for this reason several surgeons advocate routine postoperative supplementation with calcium or vitamin D to facilitate early discharge. ${ }^{43,} 49,56$ Several studies tried to identify factors that can predict the onset of postparathyroidectomy hypocalcaemia. $36,37,39,40,43-45,47,48$ Those patients who can be identified as being low risk for developing postoperative hypocalcaemia can conceivably be treated on an outpatient or short-stay basis, which would result in considerable reductions in healthcare costs. Only selected cases require replacement therapy, and overtreatment may inhibit parathyroid function. ${ }^{36,37,39,40,43-45,47,48}$

Multivariate analysis of clinical and biochemical data including patients' gender and age, symptoms, symptomdiagnosis latency, preoperative calcaemia, the preoperative PTH value and reduction in i.o. PTH, preoperative alkaline phosphatase, the weight of the gland removed, cardiac medications, and the type (mono or bilateral exploration) and duration of the surgical procedure have all been shown to be associated with the risk of postoperative hypocalcaemia. ${ }^{36,37,39,40,44,45,47,48,52-55}$ The demographic characteristics of our patients, their symptoms, and symptom-diagnosis latency were not related with the onset of postoperative hypocalcaemia, as reported in other studies. ${ }^{37,} 39$

In contrast with the findings reported by Westerdahl et al., 37 in our patients, postoperative symptomatic hypocalcaemia was not related with preoperative serum levels of calcitonin and alkaline phosphatase. Some authors ${ }^{36,37}$ report that preoperative normocalcaemia was associated with an increased risk of postoperative hypocalcaemia. This was not confirmed in our study.

There is usually a discrete correlation between the mass of the adenoma and the amount of parathyroid hormone secreted ${ }^{57}$ By contrast the weight of the adenoma does not represent a predictive factor for the onset of postoperative hypocalcaemia, as reported in the literature $^{36}$ and by our experience.

Kald et al. ${ }^{39}$ reported that a high preoperative PTH value (five times the upper limit of normal) represents a risk factor for the onset of postoperative hypocalcaemia 
(41\%), whereas only 6 per cent of patients with preoperative PTH values within normal range $(<35 \mathrm{pmol} / \mathrm{L})$ developed postparathyroidectomy hypocalcaemia. We did not observe statistically significant correlation between preoperative PTH values and the onset of postoperative hypocalcaemia.

The i.o. PTH assay has been widely used for predicting removal of hyperfunctioning parathyroid tissue. ${ }^{48,58,60}$ Although the pathogenesis of postoperative hypocalcaemia is multifactorial, ${ }^{36-39,45,46,49,52-55}$ impaired parathyroid function is likely the main contributing factor for clinical hypocalcaemia. Many studies have reported the utility of the quick i.o. PTH assay in predicting postthyroidectomy hypocalcaemia, 45, 49, 50, 61 but its value in parathyroid surgery has not been well established. ${ }^{36,44,47,48,59}$ A significant reduction in i.o. $\mathrm{PTH}$, higher than or equal to 80 per cent has been reported to represent a positive predictive value for identifying patients who develop postparathyroidectomy hypocalcaemia and who will require support treatment with postoperative calcium and vitamin D. $36,37,44,47,48,59$

In our experience, i.o. PTH reduction was found at multivariate analysis to be the only predicting factor for postoperative severe hypocalcemia. Furthermore, ROC-curve analysis revealed that i.o. PTH reduction greater than 85 per cent is strongly and positively related to the development of severe postoperative hypocalcemia, with odds ratio as high as 93 . We did not record any other statistically significant relationship with the absolute values of i.o. PTH at induction and 10 minutes after parathyroidectomy.

Some studies comparing unilateral with bilateral cervical exploration found an increased incidence of hypocalcaemia and significantly lower postoperative calcium levels in patients undergoing bilateral exploration. ${ }^{38,52,53,55}$ However, we did not find any relationship between the type of surgery performed (uni- or bilateral cervical exploration) associated with thyroid surgery and duration of the procedure with the onset of postoperative hypocalcaemia.

\section{Conclusions}

Our study showed that, among all the parameters analyzed, only reduction of i.o. PTH greater than 85 per cent after parathyroidectomy can be considered as a reliable factor for postoperative hypocalcaemia after parathyroidectomy for primary hyperparathyroidism. Therefore, the reduction in i.o. PTH, in addition to accurately predicting whether the surgical removal of parathyroid tissue was complete, can therefore identify patients at low risk for hypocalcaemia, thus promoting an early, safe discharge and helping to avoid expensive overtreatment with oral calcium and vitamin $\mathrm{D}$ analogue.

\section{REFERENCES}

1. Fraser WD. Hyperparathyroidism. Lancet 2009;374:145-58.

2. DeLellis RA, Mazzaglia P, Mangray S. Primary hyperparathyroidism: a current perspective. Arch Pathol Lab Med 2008;132: 1251-62.

3. Wermers RA, Khosla S, Atkinson EJ, et al. The rise and fall of primary hyperparathyroidism: a population-based study in Rochester, Minnesota, 1965-1992. Ann Intern Med 1997;126: 433-40.

4. Wermers RA, Khosla S, Atkinson EJ, et al. Incidence of primary hyperparathyroidism in Rochester, Minnesota, 1993-2001: an update on the changing epidemiology of the disease. J Bone Miner Res 2006;21:171-7.

5. Ahmad R, Hammond JM. Primary, secondary, and tertiary hyperparathyroidism. Otolaryngol Clin North Am 2004;37:701-13, vii-viii.

6. Delbridge LW, Younes NA, Guinea AI, et al. Surgery for primary hyperparathyroidism 1962-1996: indications and outcomes. Med J Aust 1998;168:153-6.

7. Summers GW. Parathyroid update: a review of 220 cases. Ear Nose Throat J 1996;75:434-9.

8. Heath H, Hodgson SF, Kennedy M. Primary hyperparathyroidism: incidence, morbidity and potential economic impact in a community. N Engl J Med 1980;302:189-93.

9. Clark OH, Duh QY. Primary hyperparathyroidism. A surgical perspective. Endocrinol Metab Clin North Am 1989;18:701-14.

10. Grimelius L, Akestrom G, Bondeson L, et al. The role of the pathologist in diagnosis and surgical decision making in hyperparathyroidism. World J Surg 1991;15:698-705.

11. Akestrom G, Hellman P. Primary hyperparathyroidism. Curr Opin Oncol 2003;16:1-7.

12. Wang CA, Castleman B, Cope O. Surgical management of hyperparathyroidism due to primary hyperplasia. Ann Surg 1982; 195:384-92.

13. Bilezikian JP, Marcus R, Levine MA. The functional and pathologic spectrum of parathyroid abnormalities in hyperparathyroidism. In: The Parathyroids: Basic and Clinical Concepts. New York: Raven Press, 1992, pp 435-55.

14. Molinari AS, Irvin GL III, Deriso GT, et al. Incidence of multiglandular disease in primary hyperparathyroidism determined by parathyroid hormone secretion. Surgery 1996;120:934-6, discussion 936-7.

15. DeLellis RA. Parathyroid carcinoma. Adv Anat Pathol 2004;12:53-61.

16. Givi B, Shaha JP. Parathyroid carcinoma. Clin Oncol 2010; 22:498-507.

17. American Association of Clinical Endocrinologists and the American Association of Endocrine Surgeons Task Force on primary hyperparathyroidism. Endocr Pract 2005;11:49-54.

18. Khan A. Primary hyperparathyroidism: diagnosis and management. Endocr Pract 1997;3:22-6.

19. Davies M, Fraser WD, Hosking DJ. The management of primary hyperparathyroidism. Clin Endocrinol (Oxf) 2002;57: $145-55$.

20. Rao DS, Rao DS. Treatment of primary hyperparathyroidism. Curr Opin Endocrinol Diabetes 2004;10:394-9.

21. Iglesias P, Diez JJ. Current treatments in the management of patients with primary hyperparathyroidism. Postgrad Med J 2009; 85:15-23. 
22. Bilezikian JP, Potts JT Jr, El-Hajj Fuleihan G, et al. Summary statement from a workshop on asymptomatic primary hyperparathyroidism: a perspective for the 21 st century. J Clin Endocrinol Metab 2002;87:5353-61.

23. Kouvaraki MA, Greer M, Sharma S, et al. Indications for operative intervention in patients with asymptomatic primary hyperparathyroidism: practice patterns of endocrine surgery. Surgery 2006;139:527-34.

24. Mack LA, Pasieka JL. Asymptomatic primary hyperparathyroidism: a surgical perspective. Surg Clin North Am 2004;84: 803-16.

25. Eigelberger MS, Cheah WK, Ituarte PH, et al. The NIH criteria for parathyroidectomy in asymptomatic primary hyperparathyroidism: are they too limited? Ann Surg 2004;239: 528-35.

26. Quiros RM, Alef MJ, Wilhelm SM, et al. Health-related quality of life in hyperparathyroidism measurably improves after parathyroidectomy. Surgery 2003;134:681-3.

27. Pasieka JL, Parsons LL, Demeure MJ, et al. Patient-based surgical outcome tool demonstrating alleviation of symptoms following parathyroidectomy in patients with primary hyperparathyroidism. World J Surg 2002;26:942-9.

28. Nilsson IL, Wadsten C, Brandt L, et al. Mortality in sporadic primary hyperparathyroidism: nationwide cohort study of multiple parathyroid gland disease. Surgery 2004;136:981-7.

29. Nilsson IL, Aberg J, Rastad J, et al. Maintained normalization of cardiovascular dysfunction 5 years after parathyroidectomy in primary hyperparathyroidism. Surgery 2005;137: 632-8.

30. Clark OH. "Asymptomatic" primary hyperparathyroidism: is parathyroidectomy indicated? Surgery 1994;116(6): 947-53.

31. Stefanelli T, Mayr H, Bergler-Klein J, et al. Primary hyperparathyroidism: incidence of cardiac abnormalities and partial reversibility after successful parathyroidectomy. Am J Med 1993; 95:197-202.

32. Barkun J, Duh QY, Wiseman S. Randomized trial of parathyroidectomy in mild asymptomatic primary hyperparathyroidism. Can J Surg 2006;49:59-61.

33. Felger EA, Kandil E. Primary hyperparathyroidism. Otolaryngol Clin North Am 2010;43:417-32, x.

34. Miccoli P, Pinchera A, Cecchini G, et al. Minimally invasive video-assisted parathyroid surgery for primary hyperparathyroidism. J Endocrinol Invest 1997;204:429-30.

35. Casella C, Di Fabio F, Di Betta E, et al. Surgical treatment of primary hyperparathyroidism: our experience. Ann Ital Chir 2008;79:121-7.

36. Steen S, Rabeler B, Fisher T, et al. Predictive factors for early postoperative hypocalcemia after surgery for primary hyperparathyroidism. Proc Bayl Univ Med Cent 2009;22: 124-7.

37. Westerdahl J, Lindblom P, Valdemarsson S, et al. Risk factors for postoperative hypocalcemia after surgery for primary hyperparathyroidism. Arch Surg 2000;135:142-7.

38. Johansson H, Granberg PO, Tibblin S, et al. Scandinavian study of the parathyroid surgical activity in 1975. Acta Chir Scand Suppl 1979;493:66.

39. Kald BA, Heath DI, Lausen I, et al. Risk assessment for severe postoperative hypocalcemia after neck exploration for primary hyperparathyroidism. Scand J Surg 2004;94:216-20.
40. Mittendorf EA, Merlino JI, McHenry CR. Postparathyroidectomy hypocalcemia: incidence, risk factors, and management. Am Surg 2004;70:114-9, discussion 119-20.

41. Carr ER, Contractor K, Remedios D, et al. Can parathyroidectomy for primary hyperparathyroidism be carried out as a day-case procedure? J Laryngol Otol 2006;120: 939-41.

42. Politz D, Norman J. Hyperparathyroidism in patients over 80: clinical characteristics and their ability to undergo outpatient parathyroidectomy. Thyroid 2007;17:333-9.

43. Vasher M, Goodman A, Politz D, Norman J. Postoperative calcium requirements in 6.000 patients undergoing outpatient parathyroidectomy: easily avoiding symptomatic hypocalcemia. J Am Coll Surg 2010;211:49-54.

44. Chia S, Weisman RA, Tieu D, et al. Prospective study of perioperative factors predicting hypocalcemia after thyroid and parathyroid surgery. Arch Otolaryngol Head Neck Surg 2006;132: 41-5.

45. McLeod IK, Arciero C, Noordzij JP, et al. The use of rapid parathyroid hormone assay in predicting postoperative hypocalcemia after total or completion thyroidectomy. Thyroid 2006;16: 259-65.

46. Brasier AR, Nussbaum SR. Hungry bone syndrome: clinical and biochemical predictors of its occurrence after parathyroid surgery. Am J Med 1988;84:654-60.

47. Richards ML, Grant CS. Current applications of the intraoperative parathyroid hormone assay in parathyroid surgery. Am Surg 2007;73:311-7.

48. Elaraj DM, Remaley AT, Simonds WF, et al. Utility of rapid intraoperative parathyroid hormone assay to predict severe postoperative hypocalcemia after reoperation for hyperparathyroidism. Surgery 2002;132:1028-33, discussion 1033-4.

49. Cahill RA, Harty R, Cotter S, et al. Parathormone response to thyroid surgery. Am J Surg 2006;191:453-9.

50. Di Fabio F, Casella C, Bugari G, et al. Identification of patients at low risk for thyroidectomy-related hypocalcemia by intraoperative quick PTH. World J Surg 2006;30:1428-33.

51. Kaplan EL, Barlett S, Sugimoto J, et al. Relation of postoperative hypocalcemia to operative techniques: deleterious effect of excessive use of parathyroid biopsy. Surgery 1992;92: 827-34.

52. Tibblin S, Bizard JP, Bondeson A-G, et al. Primary hyperparathyroidism due to solitary adenoma: a comparative multicenter study of early and long-term results of different surgical regimes. Eur J Surg 1991;157:511-5.

53. Worsey MJ, Carty SE, Watson CG. Success of unilateral neck exploration for sporadic primary hyperparathyroidism. Surgery 1993;114(6):1024-9; discussion 1029-30.

54. Ferrer-Ramirez MJ, Arrojo Domingo M, Lopez-Molla C, et al. Transient rise in intact parathyroid hormone concentration after surgery for parathyroid adenoma. Otolaryngol Head Neck Surg 2003;128(6):771-6.

55. Bergenfelz A, Lindblom $\mathrm{P}$, Tibblin $\mathrm{S}$, et al. Unilateral versus bilateral neck exploration for primary hyperparathyroidism: a prospective randomized controlled trial. Ann Surg 2002;236: 543-51.

56. Moore FD. Oral calcium supplement to enhance early hospital discharge after bilateral surgical treatment of the thyroid gland or exploration of the parathyroid glands. J Am Coll Surg 1994;178: $11-6$. 
57. Blindlish V, Freeman JL, Witterick IJ, et al. Correlation of biochemical parameters with single parathyroid adenoma weight and volume. Head Neck 2002;24:1000-3.

58. Irvin GL III, Derisio GT III. A new practical intraoperative parathyroid hormone assay. Am J Surg 1994;168: 466-8.

59. Shoman N, Melck A, Holmes D, et al. Utility of intraoperative parathyroid hormone measurement in predicting post- parathyroidectomy hypocalcemia. J Otolaryngol Head Neck Surg 2008;37:16-22.

60. Miura D, Wada N, Arici C, et al. Does intraoperative quick parathyroid hormone assay improve the results of parathyroidectomy? World J Surg 2002;26:926-30.

61. Lo CY, Luk JM, Tam SC. Applicability of intraoperative parathyroid hormone assay during thyroidectomy. Ann Surg 2002; 236:564-9. 